\title{
Near vision correction and quality of life among textile factory workers in Durban
}

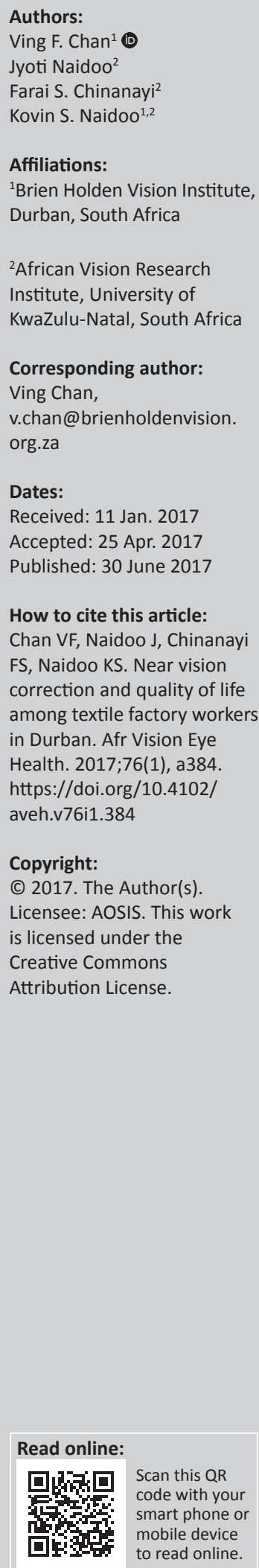

Background: Uncorrected near vision impairment affects the performance of near vision tasks and activities for an estimated 410 million people worldwide. Once normal vision becomes blurred or impaired, the ordinary and simple daily routines of individuals become difficult; often resulting in frustration and irritation, which is consequently reflected in their quality of life.

Aim: We investigated the change of vision-related quality of life (VRQoL) following near correction among textile factory workers in South Africa.

Methods: Presbyopic subjects who were 40 years and older with no other eye conditions were provided near spectacle correction. We interviewed subjects to ascertain their VRQoL scores using the National Eye Institute Visual Function Questionnaire, pre-treatment and 6 months after the provision of near corrections.

Setting: The study was conducted among the textile factory workers in KwaZulu-Natal, South Africa.

Results: A total of 423 textile factory workers were followed up from seven textile factories in Durban. The overall increase in VRQoL scores of 21.9 (95\% CI 16.7-27) was significant $(p<0.01)$. This translates to a $36.5 \%(95 \%$ CI 30.6-42.4) change in VRQoL. The increase was highest among participants of African origin 25.1 (95\% CI 21.14-29.1), males 18.8 (95\% CI 12.6-27.2), among those who had completed primary school 35.8 (95\% CI 21.7-49.9) and among participants with other responsibilities (ironing and quality assurance) 21.9 (95\% CI 16.7-27).

Conclusion: Correcting near vision impairment improved the VRQoL scores of textile factory workers. The results showed that VRQoL scores increased significantly across levels of education and categories of responsibility.

\section{Introduction}

Uncorrected near vision impairment affects the performance of near vision tasks and activities for an estimated 410 million people worldwide. ${ }^{1}$ People affected are predominantly aged 35 years and older; an age category that is usually more family orientated and socially and economically active., ${ }^{2,3}$ Once normal vision becomes blurred or impaired, the ordinary and simple daily routines of individuals become difficult, often resulting in frustration and irritation. ${ }^{2}$

Uncorrected presbyopia negatively impacts the health-related quality of life of populations from developed and developing countries, ${ }^{4,5}$ where people often perform a range of near vision day-to-day tasks such as sewing. Despite simple and cost-effective management of the condition, only $6 \%$ of people in Tanzania who are presbyopic have near spectacles, ${ }^{5}$ largely as a result of limited primary eye care services and affordable spectacles. The prevalence of uncorrected refractive error was estimated at $57 \%$ in South Africa, ${ }^{6}$ while a Durban study ${ }^{7}$ of three semi-rural areas reported that $93 \%$ of all presbyopic people needed near spectacles but did not have them. ${ }^{7}$

Most of the published literature on presbyopia highlights the potential increase in productivity following near vision correction; however, there are only a few studies ${ }^{4,5,8}$ that have measured the quality of life gains resulting from spectacle correction of near vision. Thus, in this study, we set out to examine the changes in the quality of life of textile factory workers who were examined and identified as having presbyopia and were provided with near vision spectacle correction at no charge. 


\section{Methods Study design}

This uncontrolled, open label, intervention study was part of the Near Spectacle Correction and Work Productivity Study in South Africa.

We conducted a pilot study among 50 textile factory workers in two factories, which were not part of the study sample, to inform our hypothesis, sample size calculations and methods. Our pilot study showed that $>70 \%$ of the textile factory workers were aged 40 years and older, and large proportions (>90\%) of the manufacturing labour force were women and from the lower income groups.

We included all textile factory workers who were aged 40 years and older and had worked for at least 3 months on the same near tasks in the factory prior to our data collection. We performed a standardised ocular assessment on all the potential participants. Anterior and posterior eye health assessments were performed using a direct ophthalmoscope. Distance and near visual acuities (VAs) were measured using a Low Vision Resource Centre LogMAR distance vision chart at $4 \mathrm{~m}$ and LogMAR near vision chart at $40 \mathrm{~cm}$, respectively. Objective and subjective refractions were also performed. We included only textile factory workers whose near habitual VA was less than $6 / 9$ equivalent but could be improved to better than $6 / 9$. We excluded anyone who had vision impairment because of ocular morbidities other than refractive errors. All patients identified as near vision impaired (presbyopic) were examined by a qualified optometrist and administered near corrective spectacles to correct their vision to a satisfactory level, regardless of their habitual prescriptions.

\section{Setting}

Four hundred and ninety-eight textile factory workers were recruited from seven textile factories in Durban. We chose the clothing sector as the study setting as the industry is well established in South Africa, with three levels of manufacturers, many being in operations that provide cut, make and trim services, which rely heavily on employees near vision to intricately conduct their work activities.

\section{Data collection}

Following ocular assessment, the textile factory workers were interviewed by a trained social scientist to collect pretreatment information on the current vision-related quality of life (VRQoL) score of the participants. The pre-treatment work productivity score was obtained from the factory managers 3 months before the provision of spectacles. Subsequently, the work productivity for the following 6 months was obtained from the factory managers.

Ergonomic factors were noted and considered in the initial visit to the textile factories before conducting the clinical eye examination and follow-up study. We regularly reminded the factory managers on maintaining good lighting, and keeping their work target size, colour and contrast as constant as possible, by not unnecessarily changing the responsibilities of the participants.

The textile factory workers were reminded telephonically every month about the regular use of the spectacles for near tasks. Six months after the initial provision of the near vision correction, a follow-up interview was done with the cohort. Of the 498 initial cohorts, only 423 participants were followed up (84.9\% follow-up rate). Most of the follow-up interviews were conducted face to face. If the participants were not available, or in case of their absence, on the day of visit, the candidates were interviewed by telephone 1 week after the initial visits.

The questionnaire used was the National Eye Institute 25Item Visual Function Questionnaire (NEI VFQ-25). ${ }^{9}$ The VFQ-25 consists of 25 vision-targeted questions. A high score represents better functioning. Each item is then converted to a 0-100 scale so that the lowest and highest possible scores are set at 0 and 100 points, respectively. The scores are then averaged out. Hence, scores represent the average for all items in the subscale that the respondent answered. Thus, the maximum score each person can obtain is 100 with the lowest being 0 .

The questionnaire comprising 25-item questions was back translated from English to isiZulu by a certified translator. The questionnaire was pre-tested among 20 textile factory workers during the pilot study in KwaZulu-Natal.

\section{Data analysis}

Comparisons between the pre-treatment and follow-up data sets were conducted using paired $t$-tests. Unpaired $t$-tests were used to compare VRQoL scores between selected categories within the same data set. In cases for which the overall difference was tested, the variances were tested to determine significant differences that could inform the type of $t$-test to be employed, either with equal variances or with unequal variances. Furthermore, one way analysis of variance (ANOVA) was conducted to compare VRQoL scores for factor variables with at least three categories. The results were tested at a 5\% level of significance. Furthermore, variables that were found significant in ANOVA tests were included in multivariate analysis using general linear model analysis.

\section{Ethical considerations}

Informed consent was obtained from participants, and ethical approval of the study was granted by the University of KwaZulu-Natal Biomedical Research Ethics Committee and adhered to the tenets of the Declaration of Helsinki.

\section{Results \\ Demography of participants}

Four hundred and twenty-three participants were included in the study. The median age was 49 years (IQR: $44-54$ years). 
Most were of African $(n=229,54.1 \%)$ or Indian origin $(n=189,44.7 \%)$. There were 366 (86.5\%) women in the sample. The majority of the participants had incomplete secondary school education $(n=257,60.8 \%)$ and were mainly machinists $(n=285,67.4 \%)$.

\section{Change in vision-related quality of life score}

The overall change in VRQoL score of 21.9 (95\% CI 16.7-27) was significant $(p<0.01)$. This translates to a $36.5 \%(95 \% \mathrm{CI}$ 30.6-42.4) change in VRQoL. Changes in VRQoL scores (Table 1$)$ by gender ( $p=0.01, t$-test), education $(p=0.01$, ANOVA) and responsibility categories ( $p=0.01$, ANOVA) were all significant except for ethnicity $(p=0.126)$. The highest changes within demography groups were 25.1 (95\% CI 21.14-29.1) for those of African origin $(p<0.01, t$-test), 18.8 (95\% CI 12.6-27.2) for males ( $p<0.01, t$-test), 35.8 (95\% CI 21.7-33.5) for participants who had completed primary school education $(p<0.01$, $t$-test) and 21.9 (95\% CI 16.7-27) for participants with

TABLE 1: Pre-treatment mean vision-related quality of life score of the 498 participants.

\begin{tabular}{|c|c|c|c|c|c|}
\hline Demographic profiles & $N$ & $\%$ & $\begin{array}{l}\text { Mean } \\
\text { VR QoL }\end{array}$ & s.d. & $p$ \\
\hline \multicolumn{6}{|l|}{ Ethnicity } \\
\hline African origin & 256 & 51.40 & 72.03 & 21.6 & \multirow{4}{*}{0.02} \\
\hline Caucasian origin & 2 & 0.40 & 76.50 & 9.2 & \\
\hline Mixed origin & 4 & 0.80 & 78.00 & 4.2 & \\
\hline Indian origin & 236 & 47.40 & 78.23 & 22.4 & \\
\hline \multicolumn{6}{|l|}{ Gender } \\
\hline Male & 74 & 14.90 & 73.47 & 24.5 & \multirow[t]{2}{*}{$<0.01$} \\
\hline Female & 424 & 85.10 & 83.99 & 21.2 & \\
\hline \multicolumn{6}{|l|}{ Education } \\
\hline No formal schooling & 6 & 1.20 & 74.00 & 7.4 & \multirow{7}{*}{$<0.01$} \\
\hline Primary school incomplete & 73 & 14.70 & 70.64 & 22.8 & \\
\hline Primary school complete & 31 & 14.70 & 63.84 & 17.3 & \\
\hline Secondary school incomplete & 302 & 60.60 & 75.68 & 22.1 & \\
\hline Secondary/high school complete & 83 & 16.70 & 80.45 & 21.9 & \\
\hline Skill acquired on job or vocational & 1 & 0.20 & 99.00 & - & \\
\hline Not stated & 2 & 0.40 & 78.50 & 2.1 & \\
\hline \multicolumn{6}{|l|}{ Responsibility } \\
\hline Cutter & 28 & 5.60 & 87.68 & 18.5 & \multirow{4}{*}{$<0.01$} \\
\hline Machinist & 339 & 68.10 & 73.33 & 20.4 & \\
\hline Button/zip tailor & 4 & 0.80 & 82.25 & 5.6 & \\
\hline Others (iron and quality assurance) & 127 & 25.50 & 76.56 & 26.1 & \\
\hline \multicolumn{6}{|l|}{ Glasses wear } \\
\hline Yes & 181 & 36.35 & 70.45 & 20.7 & \multirow[t]{2}{*}{$<0.01$} \\
\hline No & 317 & 63.65 & 77.65 & 22.4 & \\
\hline \multicolumn{6}{|l|}{ Eye examination } \\
\hline Never & 164 & 32.93 & 73.96 & 21.6 & \multirow{5}{*}{0.69} \\
\hline 1 year & 65 & 13.05 & 73.35 & 19.8 & \\
\hline $1-3$ years & 87 & 17.47 & 76.87 & 23.8 & \\
\hline$>3$ years & 177 & 35.54 & 75.59 & 22.4 & \\
\hline Not stated & 5 & 1.00 & 80.40 & 23.4 & \\
\hline \multicolumn{6}{|l|}{ Perception on eyesight } \\
\hline Very good & 6 & 1.20 & 79.50 & 20.2 & \multirow{6}{*}{$<0.01$} \\
\hline Good & 37 & 7.40 & 98.77 & 18.0 & \\
\hline Neutral & 141 & 28.30 & 83.42 & 19.0 & \\
\hline Bad & 283 & 56.80 & 69.33 & 20.1 & \\
\hline Very bad & 30 & 6.00 & 56.83 & 17.8 & \\
\hline Not stated & 1 & 0.20 & 64.00 & - & \\
\hline
\end{tabular}

VRQoL, vision-related quality of life; s.d., standard deviation. other responsibilities (ironing and quality assurance). The highest changes in terms of responsibility were observed among participants who have other responsibilities (ironing and quality assurance) $(p=0.01)$ as compared with their counterparts. The follow up mean vision-related quality of life score is shown in Table 2 and the changes in mean vision-related quality of life score for respondents are shown in Table 3.

Multivariate analysis using the general linear model was then performed on the three significant variables, which were gender, education levels and occupational responsibilities. When education level was held constant, gender became a significant variable $(p=0.01)$ that showed significant VRQoL gains after near spectacle correction. When responsibilities were held constant, both gender and education level became significant variables that showed significant VRQoL gains after near spectacle correction (both had $p=0.01$, respectively).

\section{Discussion}

Our results indicate that VRQoL scores increased across gender, education and responsibility for textile factory workers upon correction of near vision impairment. Because of the finite sampling that we employed, our data accurately reflect the demographic profile of the South African textile factory labour force, which is predominantly black South African and Indian, female and of a lower socioeconomic group. ${ }^{8,9,10,11,12}$ The combination of these demographic attributes has been reported previously to manifest in reduced eye health awareness and eye health practices (Brien Holden Vision Institute, unpublished).

The participants' VRQoL score increased significantly with the increase in the level of education. We hypothesise that this may be because the perception of quality of life might relate to the range of tasks in which someone is able to engage. Higher education can facilitate higher participation in a wider and diverse scope of tasks, for example, the ability to read fine print; and possibly they perceived their VRQoL to be higher than those who had lower education and more restricted activities. We also observed that those without spectacles $(n=317)$ have had significantly higher VRQoL score compared with those who wore spectacles $(n=181)$. This could be a consequence of those with spectacles being more discerning about good vision and if they are not achieving this are not satisfied and good bilateral vision has been shown to improve the VRQoL score. ${ }^{13}$

When conducting the follow-up after provision of near spectacles, we found that cutters had higher VRQoL score than others. We believe that this was because the nature of the cutters' tasks requires precision in cutting the garments as they follow the pattern lines drawn with chalk. With the spectacles provided, they have the ability to perform better, thus scoring a higher increase in VRQoL score. Furthermore, those who wore the spectacles provided only when they felt their eyes were tired also scored higher VRQoL score than 
TABLE 2: Follow-up mean vision-related quality of life score of the 423 participants.

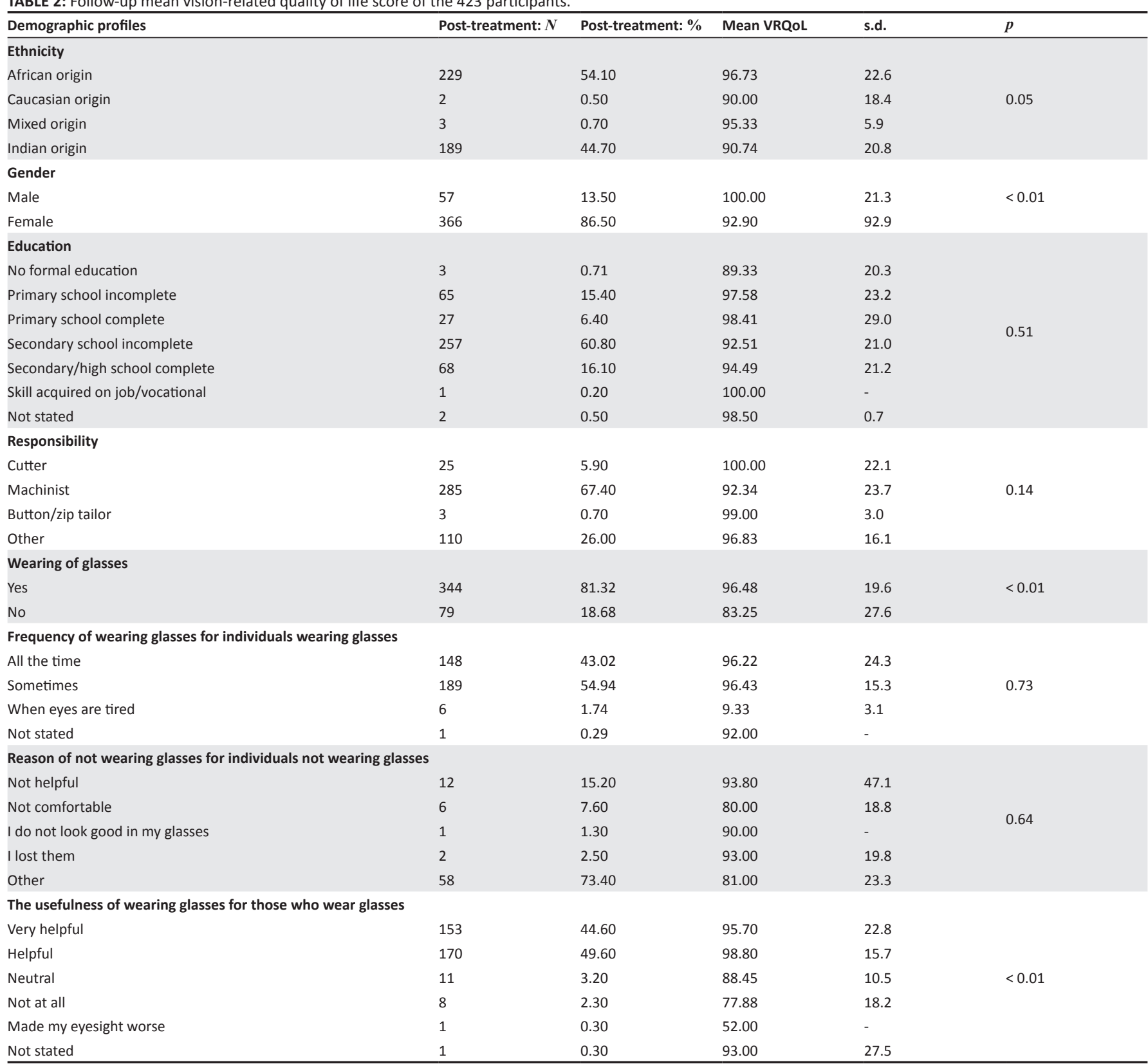

VRQoL, vision-related quality of life; s.d., standard deviation.

others who wore them all the time. In many instances, the participants put up with the stress rather than seek vision management because of low accessibility of the spectacles (factory managers, personal communication). The observation of higher VRQoL might be because of the relief from accommodative stress achieved by wearing the near corrective spectacles. ${ }^{14}$

In terms of the change in VRQoL score, we observed that across all variables, the participants showed a significant positive change. In terms of ethnicities, we saw that the increase of VRQoL score ranged from 12.3 to 25.1 (21.14-29.1) with black Africans scoring the highest. This can be explained by the fact that black Africans are predominantly hyperopic ${ }^{15,16}$ and with presbyopia, the near corrections gave them a noticeable improvement and relief.
Participants with a lower education level benefited significantly as was reflected in the increment gained in VRQoL score compared with those with higher education level. A significant observation was that it was the quality assurance officers and machinists who had a significant higher increase in VRQoL score. We observed that the near spectacle correction has the greatest effect among the quality assurance officers, because their work was a combination of garment checking and paper work. This required frequent change in head movement and accommodative adjustment and the correction not only provided ocular comfort but improved posture as well.

The study, which is exploratory in nature without a control group, may have overlooked some confounders, such as ageing and lack of randomisation in selection of factories 
TABLE 3: Changes in mean vision-related quality of life score for respondents.

\begin{tabular}{|c|c|c|c|c|c|c|}
\hline Demographic profiles & $\begin{array}{l}\text { Number of } \\
\text { respondents }\end{array}$ & $\begin{array}{l}\text { Pre-treatment VRQoL } \\
\text { score }(95 \% \mathrm{Cl})\end{array}$ & $\begin{array}{l}\text { Post-treatment VRQoL } \\
\text { score }(95 \% \mathrm{Cl})\end{array}$ & $\begin{array}{l}\text { Change in VRQoL } \\
\text { score }(95 \% \mathrm{Cl})\end{array}$ & $\begin{array}{l}\text { Change in VRQoL \% } \\
(95 \% \mathrm{Cl})\end{array}$ & $p$ \\
\hline \multicolumn{7}{|l|}{ Ethnicity } \\
\hline African origin & 229 & $71.6(68.9-74.4)$ & $96.7(93.8-99.7)$ & $25.1(21.14-29.1)$ & $48.3(38.9-57.7)$ & $<0.01$ \\
\hline Caucasian origin & 2 & $76.5(0.0-159.1)$ & $90.0(0.0-255.2)$ & $13.5(0.0-96.1 .0)$ & $17.1(0.0-106.6)$ & 0.014 \\
\hline Mixed origin & 3 & $76.3(68.7-83.9)$ & $95.3(80.8-109.9)$ & $19.0(7.6-30.4)$ & $24.9(10.3-39.5)$ & 0.009 \\
\hline Indian origin & 189 & $78.5(75.4-81.6)$ & $90.7(87.8-93.7)$ & $12.3(8.6-15.9)$ & $22.5(16.5-28.6)$ & $<0.01$ \\
\hline \multicolumn{7}{|l|}{ Gender } \\
\hline Male & 57 & $81.2(76.0-86.5)$ & $100(95.2-106.7)$ & $18.8(12.6-27.2)$ & $33.3(19.9-46.7)$ & $<0.01$ \\
\hline Female & 366 & $73.7(71.5-75.9)$ & $92.9(90.7-95.1)$ & $19.2(16.2-22.2)$ & $37.0(30.5-43.5)$ & $<0.01$ \\
\hline \multicolumn{7}{|l|}{ Education } \\
\hline No formal schooling & 3 & $72.0(54.6-89.4)$ & 89.3 (38.9-139.8) & $17.3(0.0-50.4)$ & $23.0(0-65.7)$ & 0.08 \\
\hline Primary school incomplete & 65 & $71.9(66.4-77.5)$ & $97.6(91.8-103.3)$ & $25.7(17.8-33.5)$ & $49.2(31.7-66.7)$ & $<0.01$ \\
\hline Primary school complete & 27 & $62.6(56.5-68.7)$ & 98.4 (86.9-109.9) & $35.8(21.7-49.9)$ & $69.0(40.4-97.6)$ & $<0.01$ \\
\hline Secondary school incomplete & 257 & $74.9(72.3-77.5)$ & $92.5(89.9-95.1)$ & $17.6(14.3-20.9)$ & $33.3(25.9-40.7)$ & $<0.01$ \\
\hline Skill acquired on job/vocational & 1 & $99.0(-)$ & $100(-)$ & $1.0(-)$ & $1.0(-)$ & $\dagger$ \\
\hline Not stated & 2 & $78.5(7.3-32.7)$ & 98.5 (92.1-104.9) & $20.0(7.3-32.8)$ & $25.5(3.13-47.9)$ & 0.02 \\
\hline \multicolumn{7}{|l|}{ Responsibility } \\
\hline Cutter & 25 & $89.2(81.6-96.8)$ & $100.0(90.9-109.1)$ & $10.8(0.2-21.4)$ & $16.9(1.2-32.7)$ & 0.02 \\
\hline Machinist & 285 & $73.3(70.9-75.7)$ & $92.3(89.6-95.1)$ & $19.0(15.5-22.5)$ & $35.9(28.4-43.4)$ & $<0.01$ \\
\hline Button/zip tailor & 3 & $80.0(70.1-90.0)$ & $99.0(91.5-106.5)$ & $19.0(16.5-21.5)$ & $23.8(17.8-29.9)$ & $<0.01$ \\
\hline Others (iron and quality assurance) & 110 & $74.9(70.6-79.3)$ & $96.8(93.8-99.9)$ & $21.9(16.7-27.0)$ & $42.7(31.5-54.0)$ & $<0.01$ \\
\hline Total & 423 & $74.8(72.7-76.8)$ & $94.0(91.9-96.1)$ & $21.9(16.7-27.0)$ & $36.5(30.6-42.4)$ & $<0.01$ \\
\hline
\end{tabular}

$\mathrm{Cl}$, confidence interval.

$\dagger, \mathrm{p}$-value and $95 \% \mathrm{Cl}$ could not be determined as there was only one participant who has vocational education.

and workers. We suggest a randomised controlled trial with a wider range of ages to further investigate the subject matter in future research. We also suggest further research on costutilities and compare the benefits of our intervention relative with other interventions, such as eye health promotion that might be undertaken in South African industry and society to improve overall quality of life.

\section{Conclusion}

Our overall findings demonstrated that there is an increase in VRQoL score after participants were corrected for presbyopia. However, the factories concerned at this point do not provide spectacles because spectacle provision is not in their budgets. It is the aim of the study to propose this intervention using the evidence of improvement of VRQoL scores to advocate for provision of spectacles to the workers as means of improving work productivity and reducing occupational hazards.

\section{Acknowledgements}

The study was funded by the Brien Holden Vision Institute.

\section{Competing interests}

The authors declare that they have no financial or personal relationships that may have inappropriately influenced them in writing this article.

\section{Authors' contributions}

V.F.C. was the principal investigator of the study. He was involved in the design of the study, which included writing up the proposal, designing the tool, implementation of the study, and data management and data analysis of the study. He has contributed to the overall preparation (writing) of the manuscript. J.N. is a co-investigator of the study. She is involved in the design of the study, which includes writing up the proposal, designing the tool and data collection. She has contributed $20 \%$ to the write-up of the study. F.S.C. is the statistician and co-investigator of the study. He is involved in designing of the study, focusing on sample size calculation, and data management and data analysis of the study. He contributed $20 \%$ to the write-up of the study. K.S.N. is a coinvestigator of the study. He is involved in the design of the study, focusing on the writing up of the proposal and designing of the tool. He contributed $60 \%$ to the write-up of the study.

\section{References}

1. Holden BA, Fricke TR, Ho SM, et al. Global vision impairment due to uncorrected presbyopia. Arch Ophthalmol. 2008;126:1731-1739. https://doi.org/10.1001/ archopht.126.12.1731

2. Laurent A. Understanding the needs of pre-presbyopes and emerging presbyopes. Points de vue [serial online]. 2014 [cited 2015 Oct 07] $70: 16-19$. Available from: http://www.pointsdevue.com/sites/default/files/pointsdevue70-gbesp.pdf

3. Holden BA, Sulaiman S, Knox KBA. Challenges of providing glasses in the developing world. Comm Eye Health. 2000;33:9-10.

4. McDonnell PJ, Lee P, Spritzer K, Lindblad AS, Hays RD. Associations of presbyopia with vision-targeted health-related quality of life. Arch Ophthalmol. 2003;121:1577-1581. https://doi.org/10.1001/archopht.121.11.1577

5. Patel I, West SK. Presbyopia: Prevalence, impact and interventions. Comm Eye Health. 2007;20:40-41.

6. Mashige KP, Jaggernath J, Ramson P, Martin C, Chinanayi FS, Naidoo KS. Prevalence of refractive errors in the INK area, Durban, South Africa. Optom Vis Sci. 2016;93:243-250. https://doi.org/10.1097/OPX.0000000000000771

7. Naidoo KS, Jaggernath J, Martin C, et al. Prevalence of presbyopia and spectacle coverage in an African population in Durban, South Africa. Optom Vis Sci. 2013;90:1424-1429. https://doi.org/10.1097/OPX.0000000000000096

8. Sherwin JC, Keefe EJ, Kuper H, Islam FMA, Müller A, Mathenge W. Functional presbyopia in a rural Kenyan population: The unmet presbyopic need. Clin Exp Ophthalmol. 2008;36:245-251. https://doi.org/10.1111/j.1442-9071.2008. 01711.x 
9. Revicki, D, Rentz A. National Eye Institute Visual Function Questionnaire Encyclopedia Qual Life Well-Being Res. 2014:4246-4251. https://doi. org/10.1007/978-94-007-0753-5 3002

10. Leibbrandt M, Levinsohn J. Fifteen years on: Household incomes in South Africa [homepage on the Internet]. University of Cape Town; Yale University; NBER, 2012 [cited 2016 Aug 30]; p. 7. Available from: http://www.webcitation. org/65yGefg7p

11. Gumede V. Poverty, inequality and human development in a postapartheid South Africa [homepage on the Internet]. Conference paper presented at: Overcoming inequality and structural poverty in South Africa: Towards inclusive growth and development, Johannesburg, 2010 Sept 20-22, Institute for Poverty, Land and Agrarian Studies [cited 2014 Oct 17] Available from: http://www.plaas.org.za/newsevents/povcon2010/1gumede. pdf
12. Fact sheet: Poverty in South Africa - Human Sciences Research Council - 26 July 2004 [homepage on the Internet]. South Africa Regional Poverty Network. [cited 2014 Nov 21]. Available from: http://www.sarpn.org/documents/d0000990/

13. Brown MM, Brown GC, Sharma S, Busbee B, Brown H. Quality of life associated with unilateral and bilateral good vision. Ophthalmology. 2001;108:643-647. https://doi.org/10.1016/S0161-6420(00)00635-7

14. Ehrlich DL. Near vision stress: Vergence adaptation and accommodative fatigue. Ophthal Physiol Opt. 1987;7:353-357. https://doi.org/10.1111/j.1475-1313.1987. tb00760.x

15. Pan CW, Ramamurthy D, Saw SM. Worldwide prevalence and risk factors for myopia. Ophthal Physiol Opt. 2012;32:3-16. https://doi.org/10.1111/j.1475-1313.2011.00884.x

16. Wu SY, Nemesure B, Leske MC. Refractive errors in a black adult population: The Barbados Eye Study. Invest Ophth Vis Sci. 1999;40:2179-2184. 